University of Nebraska - Lincoln

DigitalCommons@University of Nebraska - Lincoln

10-1977

\title{
Herpetomonas megaseliae and Crithidia harmosa: Growth on Blood-Agar Plates
}

Amy Doran Kepel

NOW Care medical Center (Eagan, MN)

John J. Janovy Jr.

University of Nebraska-Lincoln, jjanovy1@unl.edu

Follow this and additional works at: https://digitalcommons.unl.edu/bioscijanovy

Part of the Parasitology Commons

Kepel, Amy Doran and Janovy, John J. Jr., "Herpetomonas megaseliae and Crithidia harmosa: Growth on Blood-Agar Plates" (1977). John Janovy Publications. 14.

https://digitalcommons.unl.edu/bioscijanovy/14

This Article is brought to you for free and open access by the Papers in the Biological Sciences at DigitalCommons@University of Nebraska - Lincoln. It has been accepted for inclusion in John Janovy Publications by an authorized administrator of DigitalCommons@University of Nebraska - Lincoln. 


\title{
HERPETOMONAS MEGASELIAE AND CRITHIDIA HARMOSA: GROWTH ON BLOOD-AGAR PLATES
}

\author{
Amy Doran Keppel and J. Janovy, Jr. \\ School of Life Sciences, University of Nebraska-Lincoln, Lincoln, Nebraska 68588
}

\begin{abstract}
A technique for culturing two species of trypanosomatid flagellates on blood-agar plates is described. Herpetomonas megaseliae and Crithidia harmosa were grown as discrete clone colonies on plates prepared in sterile petri dishes with a medium derived from that of Tobie et al. (1950, J Parasitol 36: 48-54). Plates were inoculated with $0.01 \mathrm{ml}$ flagellate suspension and the inoculum was spread evenly over the surface of the agar with a sterile glass spreader. Plates were incubated in a high humidity chamber at $25 \mathrm{C}$ and colonies of both species, easily visible to the unaided eye, appeared within 1 week. There was a virtual 1:1 ratio between calculated number of CFU (colony forming units) and actual CFU observed on the plates. Colony morphology differed between the two species. Herpetomonas megaseliae produced a translucent flattened colony with a raised center and raised spiral arms, while $C$. harmosa produced an opaque hemispherical colony. Applications of the culture technique include potential diagnosis of trypanosomatid infections and potential studies in trypanosomatid genetics.
\end{abstract}

Agar plates have been used for many years for the culture of microorganisms, and agarbased media have been used for nearly as long for culture of protozoa not normally grown on plates (Nöller, 1917). Modifications of plating techniques have enabled workers to study the genetics of not only the cultured microorganisms, but also their parasites (Franklin et al., 1965; Lederberg and Lederberg, 1953; Puck, 1959). In the present paper we extend the technique of agar plate culture to include two protozoan species of the family Trypanosomatidae and suggest possible applications of the technique to problem areas in the study of trypanosomatid biology.

\section{MATERIALS AND METHODS}

Laboratory stock cultures of Herpetomonas megaseliae Daggett, Dollahon, and Janovy 1972 (ATCC \# 30209) and Crithidia harmosa McGhee, Hanson, and Schmittner 1969, were used. The C. harmosa stock was obtained from Dr. S. H. Hutner, Pace University, and is from the same stock as ATCC \# 30256. Organisms were loop transferred to 5-ml Mansour's medium with human blood (Dollahon and Janovy, 1971) and incubated at $25 \mathrm{C}$ for $72 \mathrm{hr}$ before use. Cultures used in these experiments were in the exponential phase of growth.

Culture medium was prepared from the bloodagar base of that of Tobie et al. (1950) with the Locke's solution overlay salts added directly to the agar. Medium composition was thus: $10 \mathrm{~g}$ Bacto agar (Difco), $1.5 \mathrm{~g}$ Bacto beef (Difco), 2.5 g Neopeptone (Difco), $4 \mathrm{~g} \mathrm{NaCl}, 0.1 \mathrm{~g} \mathrm{CaCl}_{2}$, $0.1 \mathrm{~g} \mathrm{KCl}, 0.15 \mathrm{~g} \mathrm{NaH} \mathrm{PO}_{4}, 1.25 \mathrm{~g}$ glucose, and

Received for publication 14 December 1976.
$500 \mathrm{ml}$ distilled water. This solution was boiled and adjusted to $\mathrm{pH} 7.2$, autoclaved in a 1 liter screw cap flask, and allowed to cool until the flask was just warm to the touch. Forty $\mathrm{ml}$ of outdated whole human blood, lysed and diluted 1:1 with distilled water, was added per $200 \mathrm{ml}$ medium.

Blood-agar plates were prepared in sterile glass petri dishes ( 15 by $100 \mathrm{~mm}$ ) poured with $20 \mathrm{ml}$ complete medium and allowed to solidify. Stock cultures of $C$. harmosa and $H$. megaseliae were counted by hemocytometer and diluted to contain the desired theoretical number of colony forming units (CFU) per $0.01 \mathrm{ml}$ dilution medium. The dilution medium was Mansour's base (Dollahon and Janovy, 1971). Plates were then inoculated with $0.01 \mathrm{ml}$ flagellate suspension and Giemsastained slides were also made of $0.01 \mathrm{ml}$ inoculum suspension. The droplet on the agar plate was spread with a sterile Pasteur pipet with the tip bent at a right angle and sealed in a flame.

Plates were sealed with masking tape, labeled, and placed in a high humidity chamber at $25 \mathrm{C}$. After 5 days growth, the numbers of colonies were counted and checked against the theoretical number of $\mathrm{CFU}$ inoculated. Inoculum slides were checked for differentiation state (of $H$. megaseliae) according to the methods of Janovy et al. (1975).

The high humidity chamber consisted of plastic shoe boxes ( 10 by 15 by $30 \mathrm{~cm}$ ) or aquaria ( 16 by 16 by $20 \mathrm{~cm}$ ) with covers, containing several cotton balls soaked in water. All inoculation procedures were carried out in an isolation hood sterilized by 24-hr continuous UV lighting.

Smears of organisms were air dried, fixed in absolute methanol, and Giemsa-stained. Stain was diluted 1:50 with phosphate buffer at $\mathrm{pH} 7.2$.

\section{RESULTS}

Initial attempts to culture C. harmosa on agar plates as described were uniformly success- 

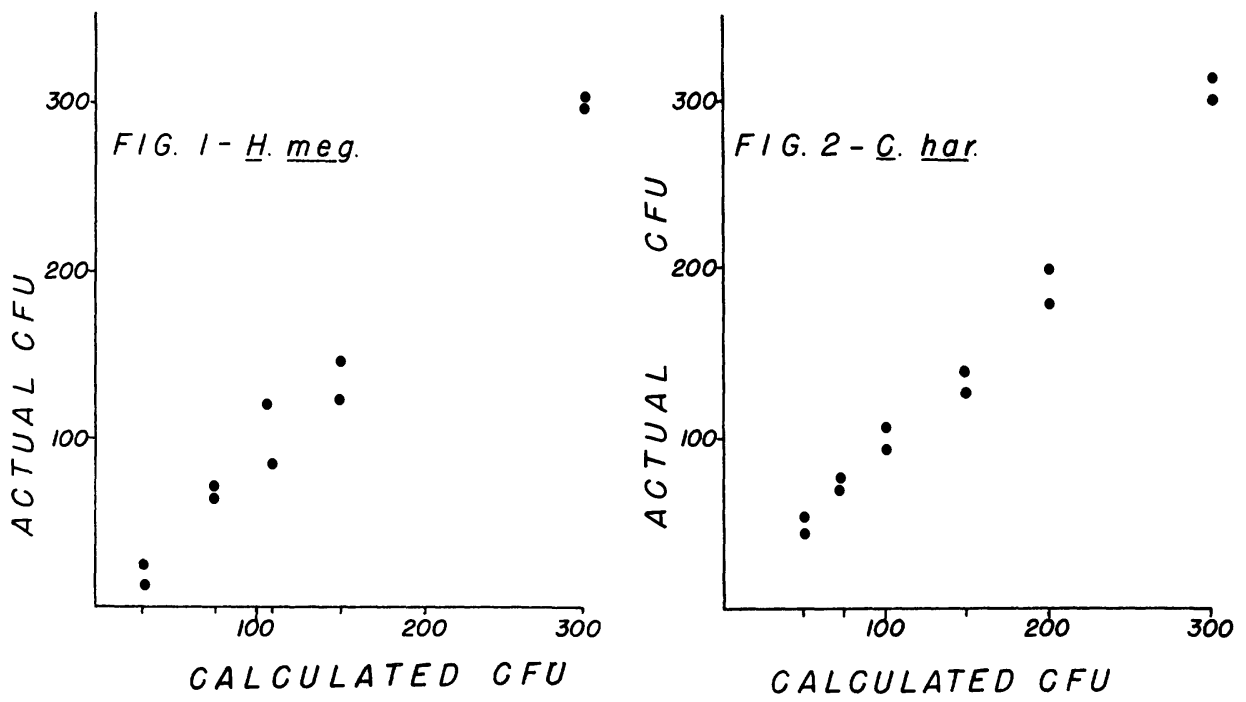

Figures 1, 2. Herpetomonas spp. in culture. 1. Relationship between calculated colony forming units (CFU) and actual observed CFU when $H$. megaseliae was cultured on agar plates. Calculated CFU was that number present in $0.01 \mathrm{ml}$ dilution medium following hemocytometer count and dilution. In this experiment plates were inoculated with $30,75,112,150$, and 300 calculated CFU. 2. Relationship between calculated CFU and actual CFU when C. harmosa was grown on agar plates. Plates were inoculated with $50,75,100,150,200$, and 300 CFU.

ful in that some colonies, interpreted as clones, always appeared. Subsequently the counting, dilution, and plate inoculation methods were refined and with these refinements, described in Methods and Materials above, the plating efficiency became very high. Figures 1 and 2 illustrate the results of a typical experiment using a series of flagellate dilutions and replicate plates. When the initial counting, dilution, and plate inoculation were done very carefully there was a virtual $1: 1$ ratio between the calculated CFU/0.01 ml Mansour's base and the observed number of colonies.

Figures 3-6 show the colonies as they actually appeared on the plates and show typical colony morphology of the two flagellate species. Herpetomonas megaseliae grew as subcircular, flat, glistening, translucent colonies that progressively enlarged, became raised in the center, and developed a flattened leading edge which we refer to as the "apron" (Figs. 3, 5). Younger colonies, 6 to 7 days postinoculation, occurred as discrete units on the plates and could easily be counted without the aid of a dissecting microscope or light box. Older cultures, 14 days postinoculation, typically exhibited not only the raised center and flat apron, but also raised spirally radiating arms within the apron which gave the colony the appearance of a pinwheel when viewed from above (Fig. 5). Closely seeded colonies tended to become confluent on the plate after 2 weeks.

Crithidia harmosa (Figs. 4, 6) also grew as discrete colonies; however, in this species the colony morphology differed from that of $H$. megaseliae. Crithidia harmosa colonies were hemispherical, opaque shading to brick red at the center, had no apron or raised arms, and tended to develop a dimple in the top after 2 weeks.

Herpetomonas megaseliae did differentiate under the above culture conditions, but the extent of differentiation after 2 weeks was considerably less than in some other culture systems (cf. Janovy et al., 1975). Inocula diluted from 3-day cultures averaged $97 \%$ promastigotes and 3\% paramastigotes. Two-week-old pinwheel colonies averaged $70 \%$ pro-, $29 \%$ para-, and $1 \%$ opisthomastigotes in the center; $46 \%$ pro-, $50 \%$ para-, and $4 \%$ opisthomastigotes in the raised arms; and $75 \%$ pro-, $24 \%$ para-, and $1 \%$ opisthomastigotes in the apron.

Subinoculation from plate to plate was successful if the organisms from the first plate 

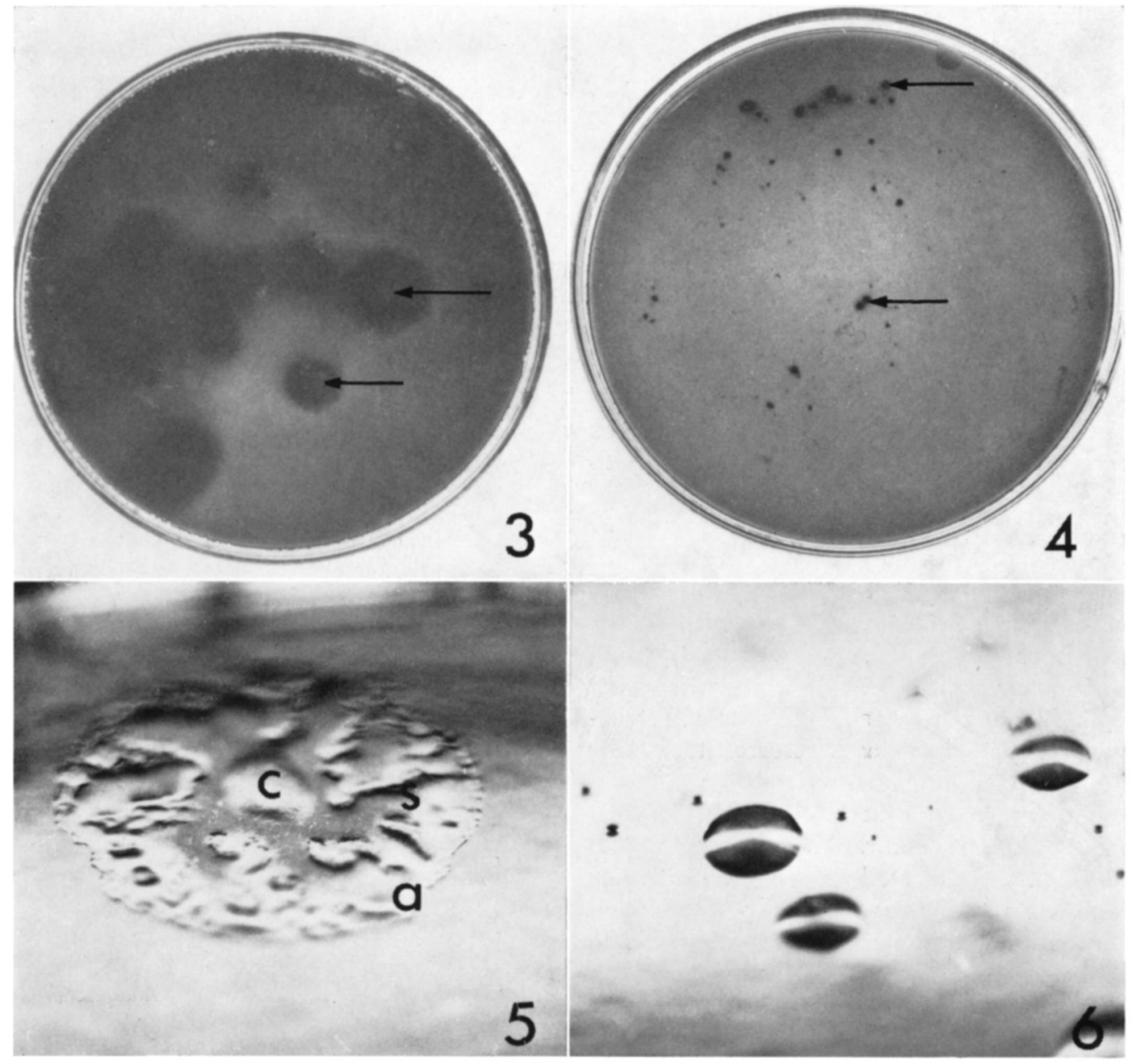

Figures 3-6. Photographs of culture plates and colonies of $H$. megaseliae and C. harmosa. 3. H. megaseliae colonies (arrows) on agar plate. 4. C. harmosa colonies (arrows) on agar plate. 5. Oblique view of $H$. megaseliae colony showing raised center (C), raised spiral arms (S), and apron (A). 6. Oblique view of C. harmosa colonies showing typical hemispherical shape.

were suspended in Mansour's base prior to inoculation on the second plate. Direct plateto-plate transfer was not attempted. The high humidity chamber was essential for optimum culture growth, and when plates were not placed in such a chamber the plating efficiency dropped considerably.

No rosettes and only an occasional pair of organisms were seen on Giemsa-stained smears of inocula. Because of this observation and because of the close agreement between calculated and actual CFU (Figs. 1, 2), each colony was interpreted as a clone.

Cloudiness and discoloration of the agar plates beneath and in the immediate vicinity of the colonies of both species occurred (Figs. $3,4)$. Examination of the discolored and cloudy agar outside the observed physical limits of the colonies revealed no flagellates, whereas flagellates were easily demonstrated by a smear of the colony itself.

\section{DISCUSSION}

The major contributions of this paper are (1) the demonstration that trypanosomatid flagellates can be grown as discrete colonies, interpreted as clones, on blood-agar plates, and (2) the demonstration that colony morphology 
on the same culture medium differs in the two genera and species studied. Thus two species of the protozoan family Trypanosomatidae, viz. Herpetomonas megaseliae and Crithidia harmosa, can be studied experimentally using techniques similar to those which have been employed for over 20 years in the study of Trichomonas vaginalis and for much longer in the study of bacteria (Asami et al., 1955). In addition, the observed differences in colony morphology can be attributed at least to the generic differences between the two species, and thus may have a genetic basis.

Although agar plate cultures of Trichomonas species have been used for many years, both for cloning and diagnosis (Asami et al., 1955; Kulda et al., 1970), and blood-agar slants or overlaid blood-agar media have been used for many years in the culture of trypanosomatids (Nöller, 1917; Senekjie, 1944; Newton, 1956), this paper (1) expands the list of trypanosomatid species to which these techniques are applicable and (2) re-emphasizes the techniques' potential use as a research tool. The latter point was apparently largely overlooked by these previous workers (Nöller, 1917; Newton, 1956). Easy and rapid cloning techniques are essential to the study of genetics, antigenic variation, nutrition, adaptation, and evolution of asexually reproducing microorganisms. The culture techniques described in this paper can potentially be applied to a wide variety of trypanosomatid species, and by extension perhaps to many other protozoan species, including free-living ones.

Although in the present studies colony morphology differed between species, and although each species had a characteristic colony morphology, these studies only suggest that among the Trypanosomatidae that can be cultured colony type may be diagnostic. A similar suggestion has been made for Trichomonas vaginalis by Hollander (1976), although in this case it was suggested that colony morphology might also be related to pathogenicity.

In addition to the above potential uses for a plating technique such as that described, the combination of culture technique plus choice of biological material multiplies the possible uses many times over. Thus choice of $H$. megaseliae not only provides a trypanosomatid which can be easily cloned, but also provides an organism which undergoes an easily assayed one-step differentiation in culture (Janovy et al., 1975) and on the plates (see above), so that the genetics of differentiation in the Trypanosomatidae now become a distinct possibility.

\section{ACKNOWLEDGMENTS}

This research was supported in part by grants from the UN-L Research Council and the National Science Foundation (PCM 7523628) to the junior author.

\section{LITERATURE CITED}

Asami, K., Y. Nodake, and T. Vero. 1955. Cultivation of Trichomonas vaginalis on solid medium. Exp Parasitol 4: 34-39.

Dollahon, N. R., AND J. Janovy, Jr. 1971. Insect flagellates from feces and gut contents of four genera of lizards. J Parasitol 57: 1130-1132.

Franklin, N. C., W. F. Dove, and C. Yanofsky. 1965. The linear insertion of a prophage into the chromosome of $E$. coli shown by deletion mapping. Biochem Biophys Res Comun 18: 910-923.

Hollander, D. H. 1976. Colonial morphology of Trichomonas vaginalis in agar. J Parasitol 62: 826-828.

Janovy, J. JR., P. M. DagGett, S. A. Knight, and J. Gunderson. 1975. Differentiation of Herpetomonas megaseliae: Population and physiological changes. Proc Okla Acad Sci 55: $130-135$.

Kulda, J., B. M. Honigberg, J. K. Frost, and D. H. Hollander. 1970. Pathogenicity of Trichomonas vaginalis. Am J Obstet Gynecol 108: 908-918.

LEDERBERG, E. M., AND J. LedERBERG. 1953. Genetic studies of lysogenicity in Escherichia coli. Genetics 38: 51-64.

Newton, B. A. 1956. A synthetic growth medium for the trypanosomatid flagellate Strigomonas (Herpetomonas) oncopelti. Nature, \#4502.

NöLLER, W. 1917. Blut-und Insektenflagellatenzuechtung auf Platten. Arch Schiffs TropHyg. Band 21 : z. 5-94.

Puck, T. T. 1959. Quantitative measurement of virus action by cell plating techniques. In M. Pollard (ed.), Perspectives in Virology, v. 1. J. Wiley and Sons, N.Y. 312 p.

SenekjIE, H. A. 1944. American visceral leishmaniasis, the etiological agent. J Parasitol 30: 303-308.

Tobie, E. J., T. von Brand, and P. Mehlman. 1950. Cultural and physiological observations on Trypanosoma rhodesiense and Trypanosoma gambiense. J Parasitol 36: 48-54. 